\title{
Determination of paeonol in huangliansu tablets by Capillary Electrophoresis
}

\author{
Hai-Xing Liu ${ }^{a}$, Quan-Hua Fan ${ }^{b}$, Yin-Ping Zhang ${ }^{c}$, Lin-Tong Wang ${ }^{d}$ and Li-Kun \\ $\operatorname{Han}^{\mathrm{e}}$ \\ Chemistry \& Chemical and Environmental Engineering College, Weifang University, Weifang \\ 261061, P.R. China \\ ahaixingliu@tom.com, ${ }^{b} 2$ h haixingliu@tom.com, ${ }^{\mathrm{c}} 3$ _haixingliu@tom.com, ${ }^{\mathrm{d}} 5$ _haixingliu@tom.com, \\ 4_haixingliu@tom.com,
}

Keywords: capillary electrophoresis, paeonol, huangliansu tablets

Abstract: This design uses High Performance Capillary Electrophoresis (HPCE) to determine the Paeonol's content in huangliansu tablets. Electrophoresis separation controlled conditions for uncoated fused silica capillary column $(75 \mu \mathrm{m} \times 52 / 60 \mathrm{~cm})$ injection height $7.5 \mathrm{~cm}$, and using a concentration of $40 \mathrm{mmol} / \mathrm{L}$ borax solution as buffer. Using separate voltage $20 \mathrm{KV}$ to detect wavelength $270 \mathrm{~nm}$, temperature is $17^{\circ} \mathrm{C}$, and the injection time control $10 \mathrm{~s}$. The Paeonol is linear relationship $(\mathrm{r}=0.998)$ within concentration of $3 \sim 400 \mathrm{mg} / \mathrm{L}$, Measured paeonol content in huangliansu tablets was $13.2 \mathrm{mg} / \mathrm{g}(\mathrm{RSD}=14.4 \%)(\mathrm{n}=6)$. The recovery of paeonol in huangliansu tablets sample was in the range of $73.1 \%-118.1 \%(n=4)$.

\section{Introduction}

Huangliansu tablet consists of berberine hydrochloride,combination, evodia rutaecarpa,Radix paeoniae alba and so on, with sissipating heat, flowing gas, antibacterial an-tiflammatory, relieving pain and diarrhea role. Simultaneous determination method of the content of six components in Fufang Huangliansu tablets using HPLC wavelength switching technology was established by LIN et al [1], The quantitative analysis of paeoniflorin, evodine, evodiamine, rutaecarpine, costunolide and dehydrocostuslacton was executed on a column of Kromasil $\mathrm{C}_{18}(250 \mathrm{~mm} \times 4.6 \mathrm{~mm}, 5 \mu \mathrm{m})$ by simultaneous HPLC wavelength switching method, using a mobile phase of acetonitrile(A)- $0.033 \mathrm{~mol} \cdot \mathrm{L}^{-1}$ potassium phosphate monobasic solution. WU et al [2] established an HPLC method for determination of the eostunolide and dehvdrocostuslactone in Fufang Huangliansu Tablets. The HPLC system consisted of century SIL $C_{18}(250 \mathrm{~mm} \times 4.6 \mathrm{~mm}, 5 \mu \mathrm{m})$ and acetonitrile- $0.1 \% \mathrm{H}_{3} \mathrm{PO}_{4}(53: 47)$ as the mobile phase and the detection wavelength was $225 \mathrm{~nm}$. LIU et al [3] established a method for simultaneous detection peoniflorin, costunolide and dehydrocostus lactone in compound Fufang Huangliansu tablets. Three components (peoniflorin, costunolide, and dehydrocostus lactone) were separated by $\mathrm{C}_{18}$ chromatographic column with a gradient mobile phase consisting of aeetonitrile and $0.2 \%$ phosphoric acid solution. ZHANG et al [4] compared HPLC and UPLC methods in the determination of evodiamin and rutacarpine in compound Huangliansu tablet. The HPLC condition: Atlantis $\mathrm{C}_{18}$ column $(4.6 \mathrm{~mm} \times 250 \mathrm{~mm}, 5 \mu \mathrm{m})$, $10 \mathrm{mmol} \cdot \mathrm{L}^{-1}$ ammonium acetate $(\mathrm{pH}=3.5)$ as mobile phase $\mathrm{A}$, acetonitrile as mobile phase $\mathrm{B}$. WANG et al [5] developed a method for the dissolution determination of berberine hydrochloride in compound Huangliansu tablets. The determination was conducted on Lichrospher ODS column with mobile phase consisted of $0.033 \mathrm{~mol} \cdot \mathrm{L}^{-1}$ acetonitrile-monobasic potassium phosphate solution (40:60) at detection wavelength of $265 \mathrm{~nm}$. To study the antioxidant activity of Huangliansu, the MDA determination, agarose gel electrophoresis and SDS-PAGE are utilized to detect the protections against the lipid peroxidation, DNA and protein oxidation degradation caused by free radicals [6]. The DMPD* method is used for the detection of the scavenging action of DMPD*. The antimicrobial effects of Huangliansu were studied by Wang et al [7] using disc diffusion method. The results indicated that Huangliansu has antibacterial spectrum, inhibitory effect of Huangliansu on bacteria gram negative Escherichia coli and gram positive bebacillus subtilis, Staphylococcus aureus, inhibitory effect on disease fungus Aspergillus niger. Zhang et al [8] explored the effects of 
Huangliansu on the weight, blood glucose, lipid metabolism and serum insulin in KKAY mice and to study its possible glucoce-lowing and lipid-regulating mechanism. In this paper, the paeonol content in huangliansu tablets was determined by capillary electrophoresis.

\section{Experimental section}

Instruments and Reagents. Experimental instruments: CL-1030-type high performance capillary electrophoresis (Beijing Cailu Scientific Instrument Co., Ltd.); HW2000-type chromatography workstation (Nanjing Qianpu Software Ltd.); Capillary (75 $\mu \mathrm{m}$ inner diameter, $60 \mathrm{~cm}$ overall length, $52 \mathrm{~cm}$ effective length) from Hebei Yongnian Ruifeng Chromatographic Devices Co., Ltd.).

paeonol (Chinese Drugs and Biological Products); huangliansu tablets (Jilin yinhe pharmaceutical Co., Ltd.); Other reagents used in the experiments were all analytical grade; Double-distilled water was used.

Experimental Methods. Before the start of the experiment, capillary was successively washed with $1 \mathrm{~mol} \cdot \mathrm{L}^{-1}$ hydrochloric acid solution, double-distilled water, $1 \mathrm{~mol} \cdot \mathrm{L}^{-1}$ sodium hydroxide solution, double-distilled water, buffer solution, each for $8 \mathrm{~min}$. After three times running, capillary was cleaned again using the above method.

Measurements were carded out at $20 \mathrm{kV}$ voltage and $17{ }^{\circ} \mathrm{C}$ experimental temperature. UV detection wavelength was $270 \mathrm{~nm}$. Injection time was $10 \mathrm{~s}$ ( $7.5 \mathrm{~cm}$ height difference).

Sample Preparation. Huangliansu tablets sample solution: huangliansu tablets powder was accurately weighed $0.3413 \mathrm{~g}$, added $30 \mathrm{~mL}$ water with $25 \%$ ethanol, cold soak time of $24 \mathrm{~h}$, filtered, washed and set the volume to $50 \mathrm{~mL}$ that was the huangliansu tablets sample solution.

paeonol standard solution: paeonol was accurately weighed $0.0012 \mathrm{~g}$, added $3 \mathrm{~mL}$ water with $25 \%$ ethanol.

\section{Results and Discussion}

\section{Selection electrophoresis conditions}

Based on past experiment experience, we chose $40 \mathrm{mmol} / \mathrm{L}$ borax solution as a running buffer solution.

According to the literature, Paeonol maximum absorption wavelength was at $274 \mathrm{~nm}$, so we chose the $270 \mathrm{~nm}$ detection wavelength.

\section{Quantitative analysis}

\section{Standard curve}

First, paeonol standard solution that the concentration were $0.4,0.2,0.1,0.05,0.025,0.0125$, $0.00625,0.003125 \mathrm{mg} / \mathrm{mL}$ was prepared. Each standard solution was run for three times under the above electrophoresis conditions and the results averaged. The chromatogram of paeonol standard solution was showed in Figure 1. Taking concentration as the abscissa and peak area as the ordinate, the standard curve was drew. Linear regression equation of paeonol (peak area: $y \mu V \cdot s$, density: $\mathrm{x}$ $\mathrm{mg} / \mathrm{mL})$ and the linear range was as follows: $\mathrm{y}=-3147.5+420341 \mathrm{x}(\mathrm{r}=0.998), 0.003-0.4 \mathrm{mg} / \mathrm{mL}$. 


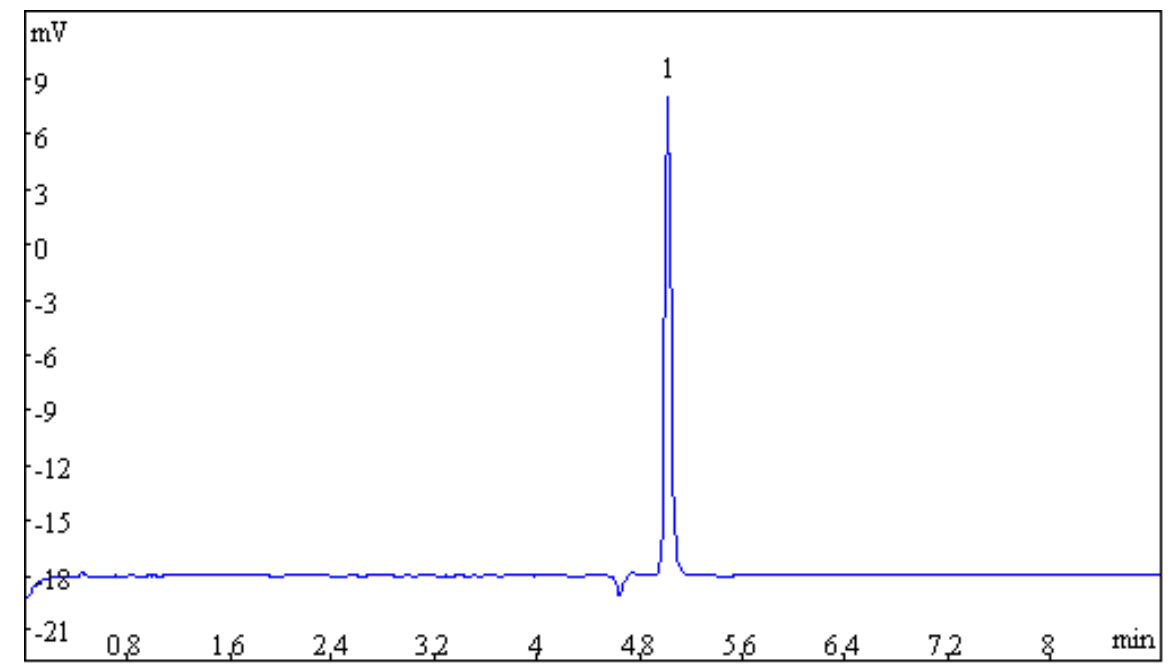

Fig.1 Electrophorogram of paeonol standard solution 1-paeonol

\section{Precision test}

paeonol standard solution precisely drew and continuously injected for six times under electrophoretic separation conditions, the RSD of paeonol peak area was 3.3\%, indicating good precision.

\section{Determination of sample content}

Under selected electrophoresis conditions, huangliansu tablets sample solution was run. Separation chromatogram of the huangliansu tablets sample solution was showed in Figure 2. Measured paeonol content in huangliansu tablets was $13.2 \mathrm{mg} / \mathrm{g}(\mathrm{RSD}=14.4 \%)(\mathrm{n}=6)$.

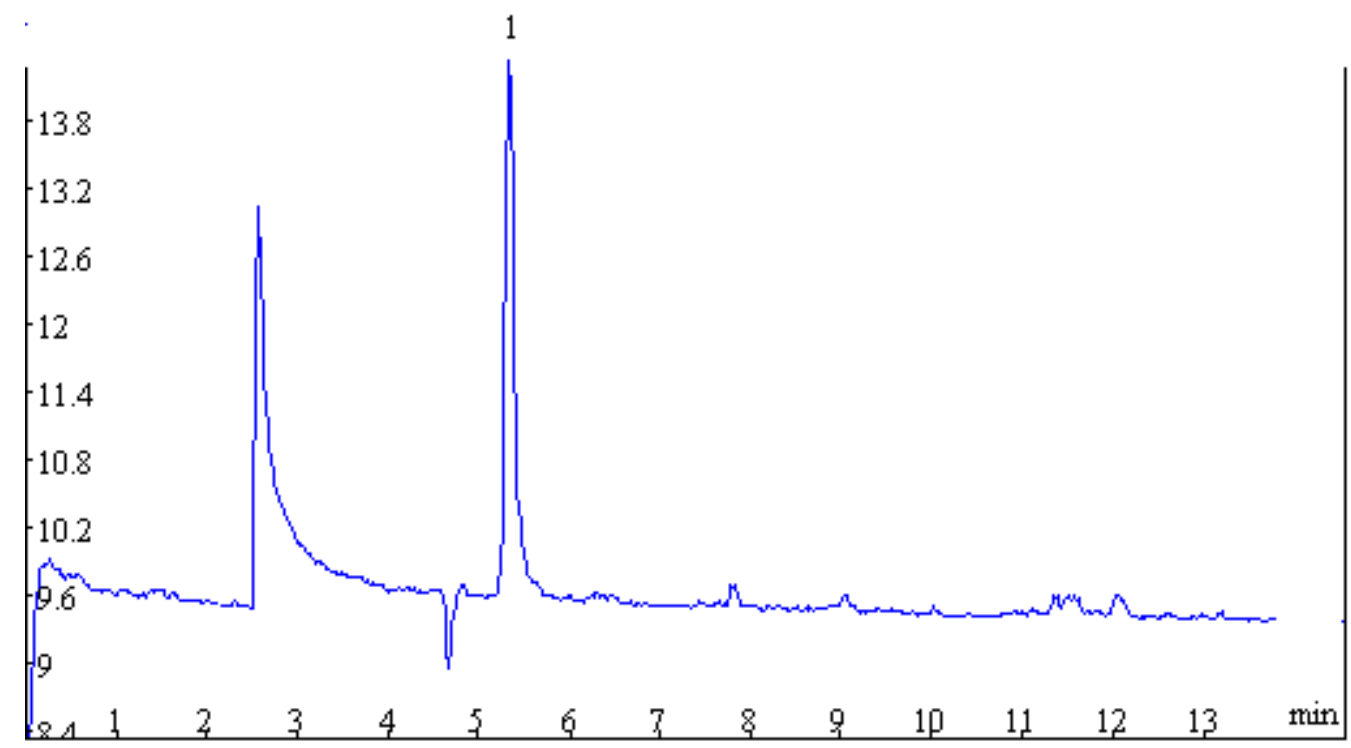

Fig.2 Electrophorogram of huangliansu tablets sample solution 1-paeonol

\section{Recovery}

After determination for four times, the recovery of paeonol in huangliansu tablets sample was in the range of $73.1 \%-118.1 \%(n=4)$. 


\section{Acknowledgments}

This study were supported by the Natural Science Foundation of Shandong Province (No. ZR2010BL025), Open Project of State Key Laboratory of Supramolecular Structure and Materials (No. sklssm201323)(Jilin University), State Key Laboratory of Inorganic Synthesis and Preparative Chemistry (No. 2011-13)(Jilin University).

\section{References}

[1] Lin LIN, Yong-qiang LIN, Bing WANG, Dong-xiao GUO, Li-hua XU, Chin J Pharm Anal (In Chinese), 2014, 34(1), 96-99

[2] Yong-qin WU, Xin-jing ZHAO, Dao-hui YAN, Qilu Pharmaceutical Affaris (In Chinese), 2009, 28(10), 596-598

[3] Xiao-zhe LIU, Dong-fang ZHANG, Chinese Journal of Experimental Traditional Medical Formula (In Chinese), 2014, 20(1), 69-71

[4] Min-juan ZHANG, xiu-mei HUANG, Shi-xian JIANG, Chin J Pharm Anal (In Chinese), 2012, 32(11), 2077-2080

[5] Hong-xia WANG, Li-yin JIANG, China Pharmacy (In Chinese), 2011, 22( 8), 758-759

[6] Guo-an LIU, Yu-ling YANG, Ya-nan ZHANG, Zhao-zheng WEI, Hong YANG, Lan DING, Li CUI, Wei WANG, Journal of Northwest Normal University (Natural Science) (In Chinese), 2009, 45(6), 87-91

[7] Xin Wang, Qin Luo, Xuemei Yang, Jun Tan, Jumei Chen, Yingyan Cha, Qing Lu, Journal of Chuxiong Normal University (In Chinese), 2014, 29(6), 53-57

[8] Qian Zhang, Xin-hua Xiao, Tong Wang, Xi-lin Zhu, Wen-hui Li, Ying Liu, Tao Yuan, Xiao-fang Sun, Qi Sun, Hong-ding Xiang, Heng Wang, ACTA Laboratorium Animalis Scientia Sinica (In Chinese), 2011, 19(1), 29-33 